\title{
The Lao in Sydney
}

\section{Ashley Carruthers}

\section{Phouvanh Meuansanith}

The Lao community of Sydney is small and close-knit, and concentrated in the outer southwest of the city. Lao refugees started to come to Australia following the takeover by the communist Pathet Lao in 1975, an event that caused some 10 per cent of the population to flee the country. The majority of the refugees fled across the Mekong River into Thailand, where they suffered difficult conditions in refugee camps, sometimes for years, before being resettled in Australia. Lao Australians have managed to rebuild a strong sense of community in western Sydney, and have succeeded in establishing two major Theravada Buddhist temples that are foci of community life.

\section{Lao settlement in south-western Sydney}

There are some 5,551 people of Lao ancestry resident in Sydney according to the 2006 census, just over half of the Lao in Australia (10,769 by the 2006 census). The largest community is in the Fairfield local government area $(1,984)$, followed by Liverpool $(1,486)$ and Campbelltown $(1,053)$. Like the Vietnamese, Lao refugees were initially settled in migrant hostels in the Fairfield area, and many stayed and bought houses in this part of Sydney. Fairfield and its surrounding suburbs offered affordable housing and proximity to western Sydney's manufacturing sector, where many Lao arrivals found their first jobs and worked until retirement. Cabramatta and Fairfield also offer Lao people resources such as Lao grocery stores and restaurants, and the temple in Edensor Park is nearby. Lao people have been attracted to Campbelltown because of cheap land prices and the quasi-rural feel of the area, with its nearby farms and large backyards that perfectly suit the Lao preference for outdoor food preparation, cooking and entertaining. The Lao community in Australia numbers a small group of professionals and managers in its ranks, but it is overwhelmingly a working-class community, with 41 per cent employed as labourers and machine operators compared to a national average of 16.7 per cent. Sixteen per cent of Lao Australians hold tertiary qualifications compared to a national average of 58 per cent. This profile reflects the difficult resettlement experience that Lao refugees have undergone in Australia. It has been a common experience for the children of Lao Australian refugees to have to forego tertiary education in order to work to look after their parents and younger siblings. 
Figure 1: Occupations of Australians of Lao ancestry in Sydney by percentage

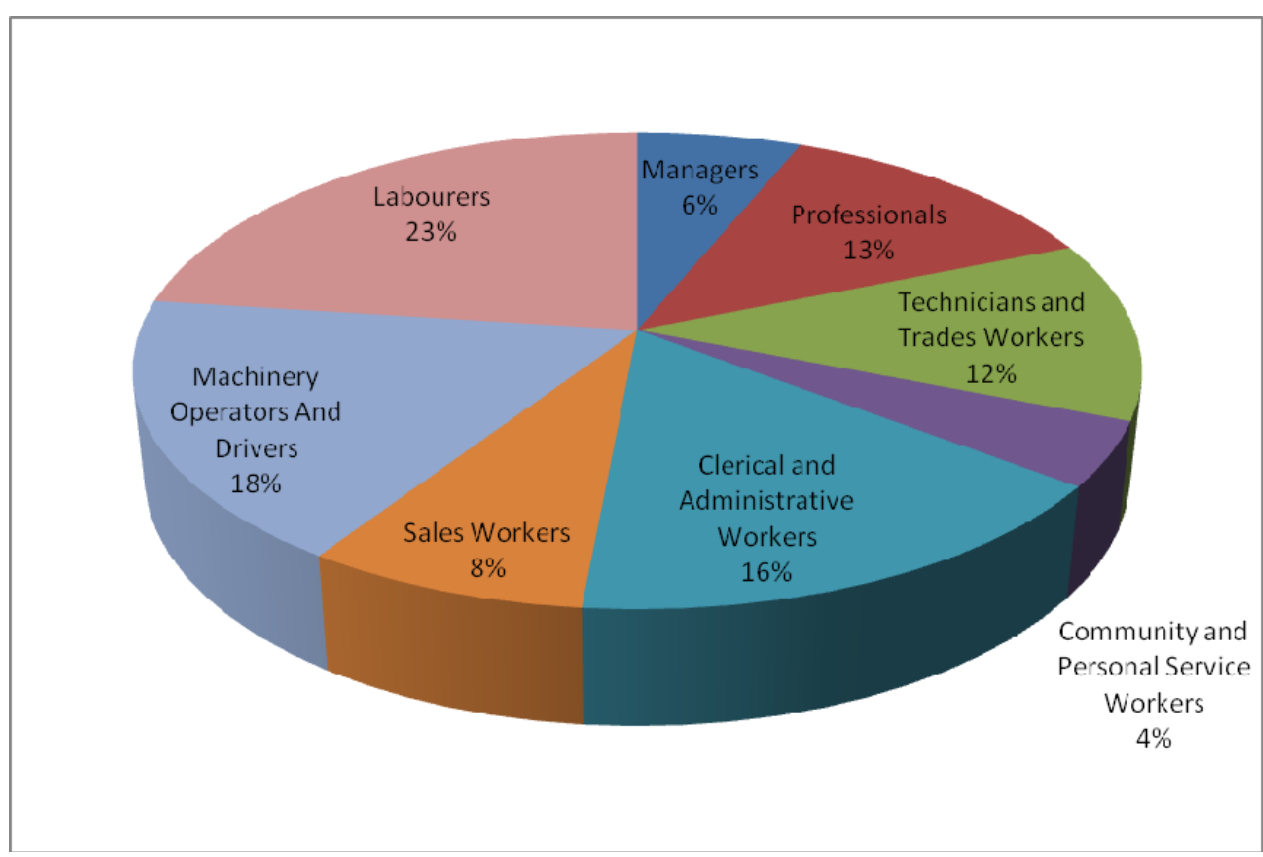

Source: Australian Bureau of Statistics, based on 2006 census

Figure 2: Occupations of Lao Australians in Sydney by numbers.

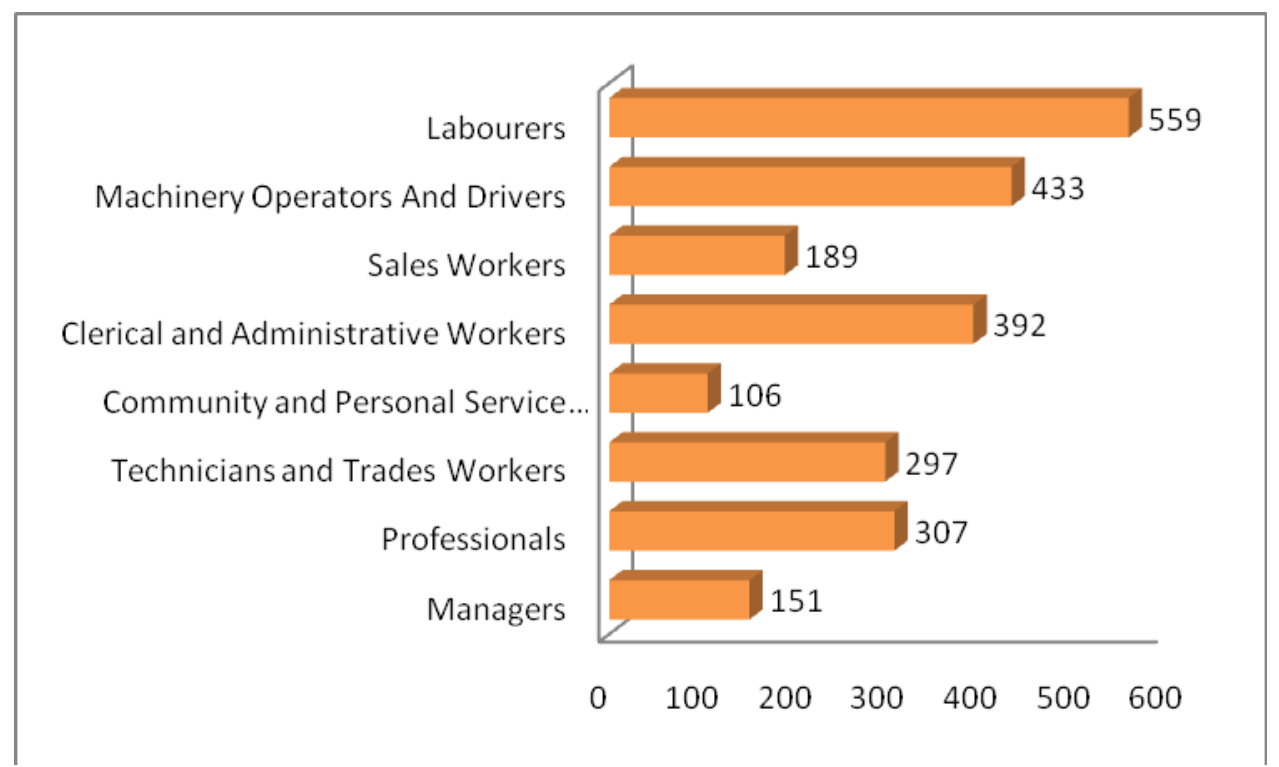

Source: Australian Bureau of Statistics, based on 2006 census. Total employed=485 
Figure 3: Educational qualifications of Lao in Sydney by percentage

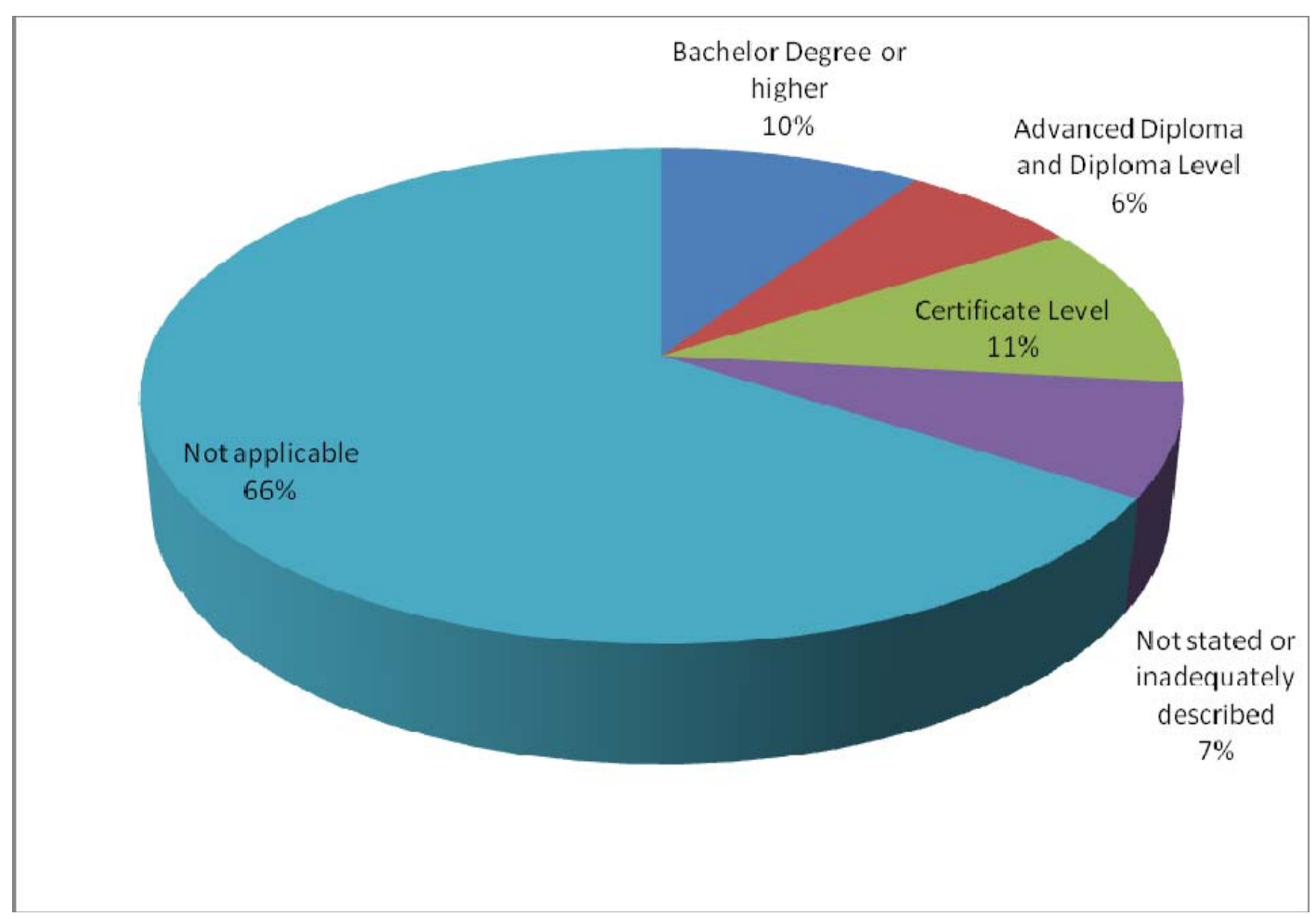

Source: Australian Bureau of Statistics, based on 2006 census

\section{Lao community associations}

A number of Lao community associations in Sydney provide settlement, religious, cultural, welfare and social support to their members. The most prominent is the Lao Community Advancement Cooperative Ltd NSW (LCAC), a body that has played a key role in Lao refugees' settlement. LCAC provides support and assistance in different areas such as English language tuition, assistance with accessing public housing, health and childcare education, and trauma, relationship and domestic violence counselling. LCAC also organises religious, fund-raising and social functions, information sessions and Lao traditional festivals.

The Lao Lane Xang Ethnic School, operated by LCAC, has been teaching Lao language, culture and traditional dancing to young Laotians since 1982. There are approximately 100 enrolments each year. The Vattana Childcare Centre has been operated by LCAC in Cabramatta since 1982. Enrolments have been at maximum capacity each year since it opened.

Other community associations include groups focused on anti-communist homeland politics, and regionally-based mutual benefit funds that help members to pay for their relatives' funerals. There is also a Lao Sport Association (Kila Lao) which organises coaching and soccer and table tennis competition among the Lao community. 


\section{Buddhism}

Reflecting the fact that Theravada Buddhism is the dominant religion of Laos, there are five Lao Buddhist temples in Sydney. The most popular is Wat Phrayortkeo Dhammayanaram, which is situated in Edensor Park in the Fairfield local government area. On the grounds of the Wat is a large community cultural centre. Every year Wat Phrayortkeo hosts a fete to celebrate Song Kan or Lao New Year, which falls around the Easter holiday. Wat Phrayortkeo is on the Fairfield City Council Cultural Heritage list and is regarded as a building of cultural significance and a local tourist attraction. Many non-Lao people visit the temple to enjoy the Song Kan festivities and food.

With the support of volunteers, Wat Phrayortkeo temple operates a Sunday Dharma School for the children of the community. The school allows younger Laotians to learn more about Buddhism and Lao culture. The school also offers various programs for the young including singing, band practice, hip hop dancing, acting, short film production and so on.

The other main Lao Buddhist temple is Wat Buddhalavarn, located in the rural setting of Wedderburn in the Campbelltown local government area. The Wat is currently constructing a large sim (ordination hall). It also holds a fete to celebrate Song Kan, and many Lao Australians attend both events.

In addition, Wat Pa Buddharangsee in Leumeah, which was established by the Thai community, has a strong Lao constituency. Lao people are present there practically every day to make the traditional food offering (bin dta baat) to the monks. Wat Pa Buddharangsee also holds an impressively large Song Kan festival.

\section{Community life}

In addition to formal community events and religious rituals, everyday life in the Lao community of Sydney is enriched by the maintenance (and reinvention) of a number of key Lao traditions. On the death of a Lao person, for instance, the grieving family will host a week-long wake (heuan dii) at the deceased person's home, culminating in the funeral. This usually involves erecting a marquee in the front or back yard and providing food, drink and entertainment to several hundred people on a nightly basis until the cremation or burial occurs. Gambling games are popular at these events, the philosophy being to give the deceased a happy send off, in a way reminiscent of the Irish tradition. Regionally based benevolent associations collect small donations from their members, which go to help the grieving family pay for the wake and funeral.

Celebrations lasting several days are also hosted at home for births and weddings. While the Lao community is not a wealthy one, families manage to host elaborate wedding receptions for several hundred people, because guests attending the reception offer money placed in an envelope as a gift at the door, creating an informal revolving fund. Weddings are typically held at home, and 
guests may arrive a day early in order to help with the elaborate food preparations. Communal cooking is a central part of Lao Australian community life. Family and friends will often gather on weekends to spend hours preparing very labour-intensive traditional Lao dishes such as laab and khao bpiak.

Lao families in Sydney regularly hold blessings or sou khwaan at home for important events such as weddings, the births of children, or a sick person's return from hospital. Monks may be invited to bless a new house or car.

A small number of Lao restaurants can be found in Fairfield and Cabramatta town centres, including Savanh and Baan Lao.

\section{Homeland ties}

The Lao community in Sydney is a refugee one, and the majority of its members maintain an inprinciple opposition to the Vientiane government. Homeland politics are not, however, so central a part of community life as they are for the neighbouring Vietnamese community.

Many Lao Australians are keenly engaged with their homeland. The great majority of families in Sydney have close relatives in Laos, and many still send remittances to family there, as well as staying in touch on a regular basis, and visiting when work and finances allow -typically once every few years. Many younger people are avid followers of homeland Lao popular culture, and the number of marriages between Lao Australian men and women from the Lao People's Democratic Republic is on the rise.

\section{Festivals}

The most important annual festival is the Theravada New Year or Song Kan festival, which is celebrated during April every year. Water throwing is a traditional way of celebrating Lao New Year. Dousing others with water is a way of conferring blessings on them and wishing them a happy new year. It also involves washing away bad luck, and more grave things such as poverty, sickness, and unhappiness etc experienced in the passing year, and preparing oneself to receive good luck, happiness and other auspicious things that come with the New Year. During Lao New Year monks in each temple bring Buddha statues down and put them outside the temple, to allow people to perform a water-pouring ritual, which is called Song Phra. People prepare special water for Song Phra by putting perfume, flower petals and turmeric in it. Then they will collect water used in the Song Phra to bring home and to pour on their family members. They believe the Song Phra water has spiritual potency and that it will help them achieve their wishes for New Year. In Laos, people prefer to experience as much water pouring as they can, because they believe that it will help them fulfil their wishes for New Year. It is very important that you should receive a watery blessing from your family members, especially your parents and grandparents. After being 
blessed by monks, and performing a solemn water blessing for Buddha statues and elderly people, the young people will then cut loose and hold a water fight. At the festivals held at the temples in Sydney this typically involves high volume water pistols and water bombs. However even during this melee it is not acceptable to throw water on monks, Buddha statues or the elderly.

Other important religious festivals include Boon Visaka Puja or 'Buddha's Birthday', Boon Kaw Pan Sa, which marks the beginning of the Rains Retreat, Boon Sut Xam Ha, a ritual to dispel misfortune, Boon Hor Kaw Pa Dap Din, a ritual that commemorates the departed, Boon Ork Pan Sa, marking the end of the Rains Retreat, and Boon Ka Tin, a ceremony at which devotees offer new robes to monks.

\section{Media}

A community newspaper entitled Khao Lao ran for a time, but by 2009 had ceased publication. SBS Radio broadcasts two hours of Lao programming per week, alternately from Sydney and Melbourne. Radio Free Asia in the US also offers a Lao language broadcast, which is listened to in Australia over the internet.

Lao people are generally proficient in Thai, and Thai television, whether accessed by satellite dish or DVD, is popular in the community, as are other forms of Thai popular culture.

Lao people in Sydney are avid consumers of popular music culture from Laos and from elsewhere in the Lao diaspora. Mor Lam is a traditional folk style featuring the khaen or Lao bamboo pan pipe. DVDs featuring Mor Lam troupes provide the joyous soundtrack to almost any Lao community get-together.

Ashley Carruthers is a lecturer in the School of Archaeology and Anthropology at the Australian National University

Phouvanh Meuansanith is a part-time social worker affiliated with the Lao Community Advancement Co-Op

\section{References}

Sumana Viravong (ed), Seri Lao [Lao Freedom]: An Anthology of Lao-Australian Refugee Writings, Casula Powerhouse, Casula NSW, 2007

Adam Chapman, 'Music and Digital Media across the Lao Diaspora', The Asia Pacific Journal of Anthropology, 5 (2), 2004, pp 129-144 